\title{
Knowledge of prostate cancer and screening practices among men in Sokoto, Nigeria
}

\author{
Kehinde Joseph Awosan', Edzu Usman Yunusa ${ }^{2}$, Ngwobia Peter Agwu ${ }^{3}$, Suleiman Taofiq ${ }^{4}$ \\ 1,2 Senior Lecturer, Department of Community Health, Usmanu Danfodiyo University, Sokoto, Nigeria. \\ ${ }^{3}$ Senior Lecturer, Department of Surgery, Usmanu Danfodiyo University, Sokoto, Nigeria. \\ ${ }^{4}$ Medical Officer, General Hospital, Kontagora, Nigeria.
}

A B S T R A C T

Background: Halting the rising burden of prostate cancer across the globe has become a major public health challenge with the absence of intellectual consensus on the effective strategies for its prevention. However, knowledge of the disease and uptake of prostate cancer screening remain indispensable in mitigating the dire consequences of the prevalent late presentation of patients with the disease in sub-Saharan Africa. Aims and Objectives: This study was designed with an aim to assess prostate cancer knowledge and screening practices among men in Sokoto, Nigeria. Materials and Methods: A descriptive cross-sectional study was conducted among 300 participants (selected by systematic sampling technique) attending the medical and surgical outpatient clinics of UDUTH, Sokoto, Nigeria. Data were collected with a pretested, structured questionnaire and analyzed using IBM SPSS version 20 computer software.Results: The mean age of the respondents was $53.13 \pm 7.92$ years. Only $15(5.0 \%)$ and $4(1.3 \%)$ of the 300 respondents were aware of prostate cancer and prostate cancer screening respectively. Most of the respondents $(95.0 \%)$ had poor knowledge of prostate cancer, and none of them have ever had a prostate cancer screening test done, with the most commonly cited reason being lack of awareness $(98.6 \%)$. Conclusion: This study showed poor knowledge of prostate cancer and zero uptake of prostate cancer screening among the participants. These findings highlight the need for government and healthcare providers to sensitize the public on prostate cancer and its prevention, in addition to facilitating unrestricted access of those at risk to prostate cancer screening services.

\section{Access this article online}

Website:

http://nepjol.info/index.php/AJMS DOI: http://dx.doi.org/10.3126/

ajms.v9i6.20751

E-ISSN: 2091-0576

P-ISSN: 2467-9100

Key words: Prostate cancer; Knowledge; Screening practices; Men

\section{INTRODUCTION}

Although, the burden of prostate cancer is high worldwide as it constitutes the second most common cancer among men, its burden is disproportionately higher in subSaharan Africa, Latin America and the Caribbean where it constitutes the most common cancer among men. ${ }^{1-3} \mathrm{~A}$ systematic review of estimates of the incidence of cancer among men in Africa reported median prostate cancer incidence rates ranging from 19.5 to 39.0 per 100,000 population. ${ }^{4}$ In Nigeria, similar to the situation in other countries in sub-Saharan Africa, prostate cancer is the most common cancer in men, with evidence of increasing morbidity and mortality from the disease.,
Studies conducted in North-Western Nigeria also reported high burden of prostate cancer. Whereas, a descriptive retrospective study of all pathologically diagnosed cancers in the records of the Histopathology Department of the Usmanu Danfodiyo University Teaching Hospital, Sokoto, Nigeria, between January 1999 and December 2004 reported prostate cancer as the second most common cancer in men $(9.9 \%)$ after bladder cancer $(15.7 \%){ }^{7}$ a 10 year analysis of the Kano Cancer Registry (1995-2004) reported prostate cancer as the most common cancer in men $(16.5 \%)$, followed by bladder cancer $(10.2 \%){ }^{8}$

Noticeably, while mortality from prostate cancer has declined of recent in the developed countries due to 
early detection, the reverse is true in sub-Saharan Africa where reports from studies showed that majority of patients with the disease present with advanced incurable tumors, with less than half surviving up to 5 years after diagnosis, compared to the $98 \%$ survival 5 years post diagnosis among African-Americans in the United States of America. ${ }^{5,9,10}$

The late presentation of patients with prostate cancer and the poor survival rates recorded in sub-Saharan Africa is not surprising, in view of the documented poor awareness of the disease and poor prostate cancer screening practices across the continent. ${ }^{11,12}$ It is therefore evident that knowledge of the disease (particularly its signs and symptoms) by those at risk, and its early detection through screening are crucial to curtailing the prevalent late presentation of cases, and high mortality from the disease across the continent. Despite the high burden of prostate cancer among men in Sokoto, Nigeria, little is known about their knowledge and screening practices regarding the disease. This study was conducted to assess prostate cancer knowledge and screening practices among men in Sokoto, Nigeria.

\section{MATERIALS AND METHODS}

\section{Study design and population}

This cross-sectional study was carried out at the Usmanu Danfodiyo University Teaching Hospital (UDUTH), Sokoto, Nigeria, from July to September 2014. The hospital has a bed capacity of 650 and serves the inhabitants of Sokoto state, neighboring Kebbi and Zamfara states, as well as people from the neighboring Niger Republic. The study population comprised of male patients attending the medical and surgical outpatient clinics of the hospital.

\section{Inclusion criteria}

1. Male patients aged 40 years and above.

2. Gave informed consent to participate in the study

\section{Exclusion criteria}

Patients that were too ill to respond to the questions and those already diagnosed with prostate cancer were excluded from the study.

\section{Sample size estimation and sampling technique}

The sample size was estimated at 295 using the Fisher's formula for estimating sample size for descriptive studies, ${ }^{13}$ a $24.0 \%$ prevalence of uptake of prostate cancer screening among adult males in a previous study, ${ }^{14}$ a precision level of $5 \%$, and an anticipated participant response rate of $95 \%$. The eligible participants were selected by systematic sampling technique; one of four men presenting consecutively at the medical and surgical outpatient clinics of the hospital and meets the eligibility criteria was enrolled into the study over a period of three months until the required sample size was obtained.

\section{Data collection and analysis}

A standardized, structured, interviewer-administered questionnaire (Appendix 1) was used to obtain information on the study participants' socio-demographic characteristics, their knowledge of prostate cancer and their prostate cancer screening practices. The questionnaire was adapted from the instrument used in previous studies. ${ }^{15,16}$ The questionnaire was pretested among 20 men attending the General Outpatient Clinic of Specialist Hospital Sokoto, Nigeria (another tertiary healthcare facility within Sokoto metropolis); the questions were well understood by the respondents and no modification was necessary. Six resident doctors assisted in questionnaire administration after being trained on the conduct of survey research, the objectives of the study, and questionnaire administration.

Data were analyzed using the IBM SPSS version 20 computer statistical software package. Respondents' knowledge of prostate cancer was scored and graded on a 15-point scale. One point was awarded for a correct response, while a wrong response or I don't know response received no points. This gives a minimum score of ' 0 ' and a maximum score of ' 15 ' points. Those that scored $\geq 11$ of 15 points were considered as having 'good' knowledge; those that scored 6 to 10 of 15 points were graded as having 'fair' knowledge, while those that scored $<6$ of 15 points were graded as having 'poor' knowledge. Quantitative variables were summarized using mean and standard deviation, while categorical variables were summarized using frequencies and percentages. Frequency distribution tables were constructed; and cross tabulations were done to examine the relationship between categorical variables. The Chisquare test was used for bivariate analysis involving categorical variables. All levels of significance were set at $\mathrm{p}<0.05$.

\section{Ethical consideration}

Institutional ethical clearance was obtained from the Ethical Committee of Usmanu Danfodiyo University Teaching Hospital, Sokoto, Nigeria. Permission to conduct the study was obtained from the Management of the hospital and heads of the respective departments in charge of the clinics where data collection was done; informed written consent was also obtained from the study participants before data collection. 


\section{RESULTS}

All the 300 questionnaires administered were completed, retrieved and analyzed giving a response rate of $100 \%$. The ages of the respondents ranged from 40 to 84 years $($ Mean $=53.13 \pm 7.92)$ with a larger proportion $(44.7 \%)$ in the 40-49 years age group. Most of the respondents were married $(84.0 \%)$, and practiced Islam as religion $(77.7 \%)$. Majority of respondents $(55.4 \%$ ) had little education (i.e., either quranic or primary education) as shown in Table 1.

Knowledge of prostate cancer among respondents Only $15(5.0 \%)$ and $4(1.3 \%)$ of the 300 respondents have ever heard of prostate cancer and prostate cancer screening respectively. Of the 15 respondents that have ever heard of prostate cancer screening, majority, 9 (60.0\%) obtained information about the disease from friends and relatives (Table 2).

Most, $285(95.0 \%)$ of the 300 respondents had poor knowledge of prostate cancer, while only a few had fair $(2.3 \%)$ and good $(2.7 \%)$ knowledge of the disease. Only a few respondents $(5.0 \%$ and below) knew the risk factors, and the symptoms and signs of prostate cancer. Also, only

\begin{tabular}{lc} 
Table 1: Socio-demographic profile of \\
respondents \\
\hline Variables & Frequency $(\%) \mathbf{n}=\mathbf{3 0 0}$ \\
\hline Age group (years) & \\
$40-49$ & $134(44.7)$ \\
$50-59$ & $83(22.7)$ \\
$60-69$ & $41(13.7)$ \\
$70-79$ & $33(11.0)$ \\
80 and above & $9(3.0)$ \\
Religion & \\
Islam & $233(77.7)$ \\
Christianity & $67(22.3)$ \\
Level of education & \\
Quranic school only & $116(38.7)$ \\
Primary & $50(16.7)$ \\
Secondary & $48(16.0)$ \\
Tertiary & $86(28.7)$ \\
\hline
\end{tabular}

\begin{tabular}{lc} 
Table 2: Awareness of prostate cancer by \\
respondents \\
\hline Variables & Frequency $(\%) \mathbf{n = 3 0 0}$ \\
\hline Ever heard of prostate cancer & \\
Yes & $15(5.0)$ \\
No & $285(95.0)$ \\
Ever heard of prostate cancer & \\
screening & \\
Yes & $4(1.3)$ \\
No & $296(98.7)$ \\
Source of information ( $=15)$ & \\
Radio/Television & $2(13.3)$ \\
Newspapers/Magazines & $2(13.3)$ \\
Friends/Relatives & $9(60.0)$ \\
Healthcare workers & $2(13.3)$ \\
\hline
\end{tabular}

$4(1.3 \%)$ and $2(0.7 \%)$ knew prostate specific antigen test and digital rectal examination respectively as screening tests for prostate cancer (Table 3). There was no association between good knowledge of prostate cancer and any of the respondents' socio-demographic variables $(p>0.05)$.

\section{Respondents' prostate cancer screening practices}

None of the respondents have ever had a prostate cancer screening test done before, and the main reason cited for not doing a prostate cancer screening test by most, $296(98.6 \%)$ of the 300 respondents was lack of awareness (Figure 1).

\section{DISCUSSION}

This study assessed prostate cancer knowledge and screening practices among men in Sokoto, Nigeria. While the low levels of awareness of prostate cancer (5.0\%) and prostate cancer screening $(1.3 \%)$ among the respondents in this study are in consonance with the findings in a study conducted in an urban population in Nigeria ${ }^{12}$ which reported that $78.8 \%$ of respondents have never had any information on cancer of the prostate, and only $5.8 \%$ had heard of prostate specific antigen (PSA) test, they differ from the findings in a study conducted in Oyo state, Nigeria ${ }^{16}$ that reported $80.0 \%$ awareness of prostate cancer, and another study conducted in Lagos state, Nigeria ${ }^{15}$ that reported $66.0 \%$ awareness of prostate cancer and $58.0 \%$ awareness of prostate cancer screening. The wide variations

\begin{tabular}{|c|c|}
\hline Variables & $\begin{array}{c}\text { Correct } \\
\text { response } \\
\text { Frequency }(\%) \\
n=300\end{array}$ \\
\hline \multicolumn{2}{|l|}{ Risk factors of prostate cancer } \\
\hline Advancement in age & $15(5.0)$ \\
\hline Family history of prostate cancer & $6(2.0)$ \\
\hline Black race & $4(1.3)$ \\
\hline Obesity & $13(4.3)$ \\
\hline Eating fatty foods & $11(3.7)$ \\
\hline \multicolumn{2}{|l|}{ Symptoms or signs of prostate cancer } \\
\hline It could be asymptomatic & $10(3.3)$ \\
\hline Frequent passage of urine & $14(4.7)$ \\
\hline Difficulty in starting or holding back urine & $15(5.0)$ \\
\hline Weak or interrupted flow of urine & $15(5.0)$ \\
\hline Difficulty in having penile erection & $14(4.7)$ \\
\hline Painful ejaculation & $13(4.3)$ \\
\hline Blood in urine or semen & $15(5.0)$ \\
\hline Pain in pelvic area or bone & $13(4.3)$ \\
\hline \multicolumn{2}{|l|}{ Screening tests for prostate cancer } \\
\hline Prostate specific antigen & $4(1.3)$ \\
\hline Digital rectal examination & $2(0.7)$ \\
\hline \multicolumn{2}{|l|}{ Knowledge grade } \\
\hline Good & $8(2.7)$ \\
\hline Fair & $7(2.3)$ \\
\hline Poor & $285(95.0)$ \\
\hline
\end{tabular}




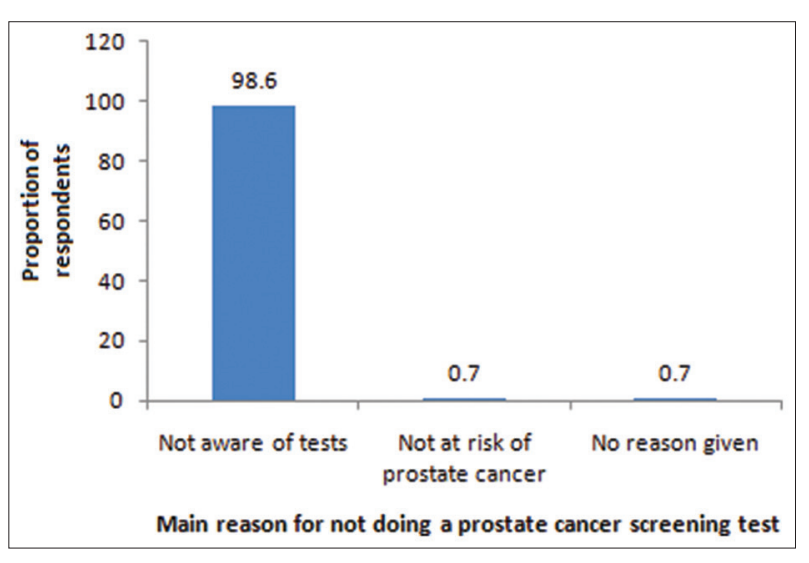

Figure 1: Main reason for not doing a prostate cancer screening test

in the awareness of prostate cancer and its screening tests across Nigeria suggests the need for the Federal Ministry of Health, Nigeria, in collaboration with the respective State Ministries of Health to organize regular sensitization programs on the disease across the country.

The findings of most of the respondents in this study $(95.0 \%)$ having poor knowledge of prostate, and with only a few (5\% and below) knowing its symptoms and signs, and the screening tests for the disease are similar to the findings in studies conducted across Nigeria, ${ }^{12,17,18}$ and other sub-Saharan African countries, ${ }^{11,19,20}$ and these could be responsible for the late presentation of cases (when only palliative care is possible), and the high mortality from the disease across the continent. In a study in Uganda, ${ }^{11}$ while about $54.1 \%$ had heard about prostate cancer, only $9 \%$ and $9.5 \%$ knew prostate specific antigen (PSA) test and digital rectal examination (DRE) respectively as screening tests for prostate cancer, and only $2.8 \%$ have ever been screened for prostate cancer. It is therefore imperative that the Government of the respective country across the continent give interventions for the primary prevention of prostate cancer (particularly education of the populace on the disease) top priority.

The zero uptake of prostate cancer screening among the respondents in this study is not surprising in view of the poor awareness of the tests by them. Similar to the finding in this study, a study by Ajape et al, ${ }^{12}$ that reported poor awareness of PSA test (5.8\%) also reported zero uptake of the test. The worrisome aspect is the generally low uptake of PSA test in studies conducted in many cities across Nigeria, even among populations with high awareness of prostate cancer and its screening tests. In a study among older men in Oyo State, Nigeria ${ }^{16}$ even though, most of the respondents $(80 \%)$ were aware of prostate cancer, only a few $(4.5 \%)$ had undergone PSA test. In another study among the male staff of the University of Lagos, ${ }^{15}$ even though $59.3 \%$ of respondents were aware of PSA test, only $28.4 \%$ had undergone the test, with the reasons cited by those who have not done the test being lack of awareness (32.4\%), and that their doctor did not recommend it for them $(30.2 \%)$. Healthcare professionals have pivotal role to play in reducing the high burden of prostate cancer across the country by educating their patients and clients on the disease, as well as promote prostate cancer screening among them. This is supported by the findings of a free community based prostate cancer screening programme (over a period of 4 years) by Akinremi et $\mathrm{al}^{21}{ }^{21}$ which reported that the number of men attending and consenting to screening increased from year to year. This finding is reassuring as it clearly shows that Nigerian men are willing to accept prostate cancer screening if they have access to the services. In addition, about a tenth (11.5\%) of the participants in the study had elevated PSA $(>4 \mathrm{ng} / \mathrm{ml})$ and about a third (31.45\%) showed abnormal digital rectal examination (DRE) findings. Also, majority of those who had the PSA test done $(79.2 \%)$ also consented to digital rectal examination, with $5.8 \%$ of them having combined abnormal DRE and PSA results. The yield in the study is impressive and it highlights the benefits of organizing free screening programmes for groups at risk.

Studies conducted in other countries across sub-Saharan Africa mostly reported poor uptake of prostate cancer screening, with the major obstacles being poor awareness of the tests, poor promotion of the tests by healthcare professionals, and poor accessibility (physical, financial and intellectual) to prostate cancer screening services. In a study conducted among Ugandan men, ${ }^{11}$ only $9 \%$ and $9.5 \%$ of respondents knew PSA and DRE respectively as screening tests for prostate cancer. Also, whereas, physicians have ever recommended prostate cancer screening tests to $12.3 \%$ of respondents, only $2.8 \%$ had undergone the tests; and among the respondents that have never had a prostate cancer screening test done, the most commonly cited reason was lack of awareness (32.0\%). In another study among Namibian men aged 40 -64 years, only 16.0\% of respondents had undergone prostate cancer screening tests. In addition, having health insurance cover, having secondary education or more, and discussing reproductive health issues with a health personnel 12 months before the survey were associated with a 6.77, 6.34, and 2.02 higher likelihood of undergoing prostate cancer screening tests respectively, while residing in a rural area was associated with a $51.0 \%$ less likelihood of undergoing prostate cancer screening tests. ${ }^{22}$ These findings highlight the need for governments, healthcare providers and other stakeholders to improve accessibility to information and services regarding prostate cancer screening in order to halt the rising burden of the disease across the continent. 


\section{CONCLUSION}

This study showed poor knowledge of prostate cancer and zero uptake of prostate cancer screening among men in Sokoto, Nigeria. These findings highlight the need for government and healthcare providers to sensitize the public on prostate cancer and its prevention, in addition to facilitating unrestricted access of those at risk to prostate cancer screening services.

\section{Limitation of the study}

This was a hospital based study; the findings might therefore have limited generalizability.

\section{ACKNOWLEDGEMENTS}

The authors appreciate the management of Usmanu Danfodiyo University Teaching Hospital, Sokoto, Nigeria, the heads of the departments in charge of the outpatient clinics where the study was conducted, the clinics' staff, and all the patients that participated in the study for their cooperation.

\section{REFERENCES}

1. Baade PD, Youlden DR and Krnjacki LJ. International epidemiology of prostate cancer: geographical distribution and secular trend. Molecular Nutrition and Food Research 2009; 53(2): 171-184.

2. Rebbeck TR, Zeigler-Johnson CM, Heyns CF and Gueye SM. Prostate cancer screening, detection, and treatment practices among sub-Saharan African urologists. Afr J Urology 2011; 17(3): 85-91.

3. Wong MC, Goggins WB, Wang HH, Fung FD, Leung C, Wong SY, et. al. Global incidence and mortality for prostate cancer: analysis of temporal patterns and trends in 36 countries. Eur Urol. 2016; 70(5): 862-874.

4. Adeloye D, David RA, Aderemi AV, Iseolorunkanmi A, Oyedokun $A$ and Iweala EEJ. An estimate of the incidence of prostate cancer in Africa: a systematic review and meta-analysis. PLoS ONE 2016; 11(4): e0153496. doi: 10.1371/journal.pone. 0153496.

5. Parkin D, Nambooze S, Wabwire-Mangen F and Wabinga HR. Changing cancer incidence in Kampala, Uganda. 1991-2006. Int J Cancer 2010; 126(5): 1187-1195.

6. Baba IA and Hincal E. Cancer incidence in Nigeria and border countries. Malay J Med Biol Res 2016; 3(1): 7-12.
7. Malami SA, Pindiga UH, Abimiku BA, Mungadi JA, Abdullahi AD, Dauda $A$, et al. A descriptive retrospective study of the pattern of malignant diseases in Sokoto, North-western Nigeria (19992004). J Med Sci 2007; 7(6): 1033-1038.

8. Mohammed AZ, Edino ST, Ochicha O, Gwarzo AK and Samaila AA. Cancer in Nigeria: a 10-year analysis of the Kano Cancer Registry. Nig J Med 2008; 17(3): 280-284.

9. Dawan D, Rafindadi AH and Kalayi GD. Benign prostatic hyperplasia and prostatic cancer in native Africans. BJU Int 2000; 85(9): 1074-1077.

11. Nakandi H, Kirabo M, Semugabo C, Kittengo A, Kitayimbwa P, Kalungi $S$, et al. Knowledge, attitudes and practices of Ugandan men regarding prostate cancer. Afr J Urol 2013; 19(4): 165-170.

12. Ajape AA, Babata $\mathrm{A}$ and Abiola OO. Knowledge of prostate cancer screening among native African urban population in Nigeria. Nig Q J Hosp Med 2006; 19(3): 145-147.

13. Araoye MO. Research methodology with statistics for health and social sciences Ilorin: Nathadex; 2004.

14. Ashford AR, Albert SM, Hoke G, Cushman LF, Miller DS and Basset M. Prostatic cancer knowledge, attitude and screening behavior among African-American men in Central Harlem, New York City. Cancer 2001; 91(1): 164-172.

15. Ebuehi OM and Otumu IU. Prostate screening practices among male staff of the University of Lagos, Nigeria. Afr J Urol 2011; 17(4): 122-134.

16. Oladimeji O, Bidemi YO, Olufisayo JA and Sola AO. Prostate cancer awareness, knowledge and screening practices among older men in Oyo State, Nigeria. Int Q Community Health Educ 2009-2010; 30(3): 271-286.

17. Agbugui JO, Obarisiagbon EO, Nwajei CO, Osaigbovo EO, Okolo JC and Akinyele AO. Awareness and knowledge of prostate cancer among men in Benin City, Nigeria. J Med Biomed Res 2013; 12(2): 42-47.

18. Abdulrahman Al, Gobir AA, Abubakar AA, Onoja $M$ and Joshua IA. Knowledge and practice of prostate cancer screening among men in Birni Kudu, North Western Nigeria. Int J Med Health Dev 2016; 21(2): 10-15.

19. Makado E, Makado RK and Rusere MT. An assessment of knowledge of and attitudes towards prostate cancer screening among men aged 40 to 60 years at Chitungwiza Central Hospital in Zimbabwe. The Int J Humanities Soc Studies 2015; 3(4): 45-55.

20. Mofolo N, Betshu O, Kenna O, Koroma S, Lebeko T, Claassen FM, et al. Knowledge of prostate cancer among males attending a urology clinic: a South African study. Springer Plus 2015; 4: 67. doi: 10.1186/s40064-015-0824-y.

21. Akinremi T, Adeniyi A, Olutunde A, Oduniyi A and Ogo C. Need for and relevance of prostate cancer screening in Nigeria. Ecancer 2014; 8: 457. doi: 10.3332/ecancer.2014.457.

22. Kangmennaang $\mathrm{J}$, Mkandawire $\mathrm{P}$ and Luginaah I. What prevents men aged 40-64 years from prostate cancer screening in Namibia. J Cancer Epid 2016, Article ID 7962502, 9 pages. doi: $10.1155 / 2016 / 7962502$

\footnotetext{
Authors Contribution:

KJA- Concept and design of the study, collection of data, reviewed the literature, manuscript preparation and critical revision of the manuscript; EUY- Concept and design of the study, collection of data and review of literature; NPA- Concept and design of the study, collection of data, review of literature, and critical review of the manuscript; ST- Concept and design of the study, collection of data and review of literature.

Work attributed to:

Department of Community Health, Usmanu Danfodiyo University, Sokoto, Nigeria

ORCID ID:

Dr. Kehinde Joseph Awosan- (i) http://orcid.org/0000-0002-8944-6791

Source of Support: Nil, Conflict of Interest: None declared.
} 


\section{QUESTIONNAIRE ON KNOWLEDGE OF PROSTATE CANCER AND SCREENING PRACTICES AMONG MEN IN SOKOTO, NIGERIA}

\section{SECTION A: RESPONDENT'S SOCIO - DEMOGRAPHIC PROFILE}

1) Age at last birthday: (in years) (please specify)

2) Religion: (a) Islam $\square$ (b) Christianity $\square$ (c) others (please specify)

3) Level of Education: (a) Qurranic school only (b) Primary $\square$ (c) Secondary $\square$ (c) Tertiary $\square$

\section{SECTION B: PROSTATE CANCER KNOWLEDGE}

4) Have you ever heard of prostate cancer? (a) yes $\square$ (b) no $\square$

5) If your answer to question 4 is yes, through which medium?

(a) radio/television $\square$ (b) newspaper/magazines $\square$ (c) friends/relatives $\square$

(d) health workers $\square$ (e) church/mosque $\square$

6) Which of the following can cause or lead to prostate cancer?

(i) As age increases (old age): (a) yes $\square$ (b) no $\square$ (c) I don't know $\square$

(ii) Family history of prostate cancer: (a) yes $\square$ (b) no $\square$ (c) I don't know

(iii) Being black (black race): (a) yes $\square$ (b) no $\square$ (c) I don't know $\square$

(iv) Obesity: (a) yes $\square$ (b) no $\square$ (c) I don't know $\square$

(v) Consumption of fatty foods: (a) yes $\square$ (b) no $\square$ (c) I don't know $\square$

7) Which of the following is a symptom or sign of prostate cancer?

(i) A need to urinate frequently especially at night:

(a) yes $\square$ (b) no $\square$ (c) I don't know $\square$

(ii) Difficulty starting urination or holding back urine:

(a) yes $\square$ (b) no $\square$ (c) I don't know $\square$

(iii) Weak or interrupted flow of urine: (a) yes $\square$ (b) no $\square$ (c) I don't know $\square$

(iv) Difficulty in having an erection: (a) yes $\square$ (b) no $\square$ (c) I don't know

(v) Painful urination or ejaculation: (a) yes $\square$ (b) no $\square$ (c) I don't know $\square$ (vi) Blood in urine or semen: (a) yes $\square$ (b) no $\square$ (c) I don't know $\square$

(vii) Pain in the pelvic area or bones (lower back, hips or thighs):

(a) yes $\square$ (b) no $\square$ (c) I don't know $\square$

\section{SECTION C: KNOWLEDGE AND PRACTICE OF PROSTATE CANCER SCREENING}

8) Have you ever heard of prostate cancer screening test? (a) yes $\square$ (b) no $\square$

9) If your response to question 8 is yes, which of the following is a screening test for prostate cancer?

(i) Pap smear test: (a) yes $\square$ (b) no $\square$ (c) I don't know $\square$

(ii) Mammography: (a) yes $\square$ (b) no $\square$ (c) I don't know $\square$

(iii) Digital Rectal Examination: (a) yes $\square$ (b) no $\square$ (c) I don't know $\square$

(iv) Prostate Specific Antigen (PSA) test: (a) yes $\square$ (b) no $\square$ (c) I don't know $\square$

10) Have you ever had Prostate Specific Antigen (PSA) blood test done for you?

(a) yes $\square$ (b) no $\square$

11) If your response to question 10 is yes, why did you do it?

(a) It was recommended by the doctor $\square$

(b) It was recommended by a nurse (or other health workers)

(c) I did voluntarily to prevent prostate cancer $\square$

(d) A friend/relative advised me to do it $\square$

12) If your response to question 10 is yes, how many times have you had PSA done for you?

13) How long ago did you had the most recent PSA test done?

14) If your response to question 10 is no, why?

(a) I am not aware of PSA test $\square$

(b) I don't need it, as I am not at risk of developing prostate cancer $\square$

(c) The test is not available $\square$

(d) The test is costly (I can't afford it)

(e) I have passed the recommended age for PSA test $\square$

15) If your response to question 10 is no, are you willing to undergo the test even if you are to pay for it? (a) yes $\square$ (b) no $\square$

Thank you 